InterAção | 55

\title{
NOTAS SOBRE A EPISTEMOLOGIA JURÍDICA DE HANS KELSEN: $O$ SENTIDO DO DIREITO E DA CIÊNCIA NA TEORIA PURA DO DIREITO
}

Nicole da Silva Paulitsch ${ }^{1}$

\section{Resumo}

O presente trabalho objetiva uma análise epistemológica do terceiro capítulo da obra Teoria Pura do Direito, Direito e ciência, do jurista austríaco Hans Kelsen. Através da uma breve exposição dos principais aspectos bibliográficos e das ideias centrais do autor, em especial de sua concepção epistemológica jurídica no campo do normativismo, ressalta suas características e contribuições ao Direito. Descreve, ainda, o centro de interesse da Teoria Pura, qual seja a tentativa de conferir à ciência jurídica um método e um objeto próprios, depurando-os de quaisquer influências da ideologia política e dos elementos da ciência natural. Ao final, expõe e arrazoa algumas das objeções designadas à concepção de ciência subjacente ao pensamento kelseniano.

Palavras-chave: Teoria pura do direito. Epistemologia jurídica. Normativismo. Direito e ciência. Hans Kelsen.

1 Mestranda em Direito Ambiental na Universidade de Caxias do Sul. Especialista em Direito Empresarial pela Pontifícia Universidade Católica do RS. Graduada em Direito pela Universidade Federal do Rio Grande. Professora titular da Faculdade Anhanguera do Rio Grande. Advogada inscrita na OAB/RS. E-mail para contato: nicolepaulitsch@ gmail.com 
56 | InterAção

\section{INTRODUÇÃO}

O jurista e filósofo austríaco Hans Kelsen, considerado um dos maiores pensadores do século XX, deixou um vasto legado teórico-literário, do qual se destaca sua obra Teoria Pura do Direito. A importância desta obra se dá, especialmente, pelo rompimento com os ditames da filosofia jurídica tradicional da época, a qual, segundo Kelsen, era contaminada com a ideologia política de todos os elementos da ciência natural. Pretendia o autor, assim, desenvolver uma teoria jurídica pura, ou seja, consciente da legalidade específica do seu objeto (KELSEN, 2009, p. XI).

Neste aspecto, o objetivo do presente trabalho é empreender uma incursão ao pensamento de Kelsen, em especial na análise da relação entabulada entre ciência e direito proposta pelo autor no capítulo terceiro de sua obra magna - a Teoria Pura do Direito, considerando sua atuação no paradigma normativista, apresentando suas diretrizes basilares, bem como uma análise das suas limitações, por meio de um arrazoado das críticas mais pertinentes recebidas.

Para tanto, antes de se passar à análise da obra referida, notadamente no referido capítulo acerca do Direito e Ciência, a primeira parte do presente artigo destina-se a descrever breves linhas sobre a biografia do autor, a qual se justifica pelo auxilio na compreensão de muitas de suas escolhas metodológicas.

Após, em uma segunda etapa, procura apresentar uma exposição das principais ideias contidas nos prefácios a primeira e segunda edições, assim como daquelas inseridas no capítulo fulcral do presente estudo, qual seja o terceiro capítulo de Teoria Pura do Direito - Direito 
e Ciência. Tendo em conta a extensão e a importância da obra em apreço, o recorte temático faz com que o objetivo do presente artigo não assuma a pretensão de esgotar todos os aspectos do pensamento teórico constantes na obra, mas tão-somente aqueles arrolados no capítulo terceiro, que aborda a relação entre direito e ciência.

Ao final, a terceira parte trata da análise às objeções suscitadas pela doutrina no que pertine à formulação de Kelsen na determinação de objeto e métodos próprios ao Direito, livre de toda e qualquer influência da ideologia política e dos elementos da ciência natural, além do normativismo proposto pelo autor, através de um viés hermenêutico.

\section{Hans Kelsen: breve perspectiva biográfica}

Hans Kelsen nasceu em Praga em 11 de outubro de 1881. Graduou-se na Faculdade de Direito na Universidade de Viena, instituição em que iniciou sua carreira lecionando a partir de 1911 até 1930. Convocado em 1917, serviu como assessor jurídico no Ministério da Guerra, colaborando com a redação da nova Constituição Republicana. Atuou, ainda, como juiz da Corte Constitucional da Áustria no período de 1921 a 1930. Após, mudou-se para Colônia, onde permaneceu até ser expulso pelo governo nacional-socialista da Alemanha em 1933, ocasião em que se dirigiu para Genebra e, doravante, para Praga. Em 1940, transferiu-se para os Estados Unidos, onde lecionou junto às Universidades de Harvard e Berkeley, até sua aposentadoria em 1952. Faleceu em 19 de abril de 1973 (MORERIRA, 2009, p. 261). 
Importa salientar que, no período em que Hans Kelsen lecionou junto à Universidade de Viena, esteve em contato o neopositivismo do chamado "Círculo intelectual de Viena", os quais exerceram - assim como Kant - grande influência sobre a obra de Kelsen. A Escola de Viena era caracterizada pela busca da metodologia perfeita, ou seja, as palavras da lei deviam fazer valer as regras semânticas, pois, para seus seguidores, inexistia na lei letra a mais do que o necessário, e, por este motivo, encontra-se em seu corpo. Para o Círculo de Viena, a crise da ciência residia no problema da linguagem, que restaria solucionado com a descoberta de uma linguagem neutra, capaz de traduzir perfeitamente o axioma vigente (SCHWARTZ, 2000, p. 97).

A propósito, pode-se verificar a extensão de tal influência desde as premissas neokantianas, como na formulação do princípio de pureza, da possibilidade de interlocução do Direito com outras áreas, a matriz positivista, na rejeição do transcendentalismo e também na noção de escalonado do ordenamento jurídico no positivismo jurídico kelseniano.

No entanto, adverte Reale acerca do alcance desta influência do Círculo de Viena sobre Kelsen, referindo que:

Há duas Escolas de Viena: - uma, a dos neopositivistas, no campo da Filosofia científica; e outra, a de Kelsen, nos domínios do Direito. Já temos visto, muitas vezes, confusões sobre este ponto, embora se deva reconhecer que, em certas consequências, as duas correntes apresentam, máxime nos últimos anos, crescentes pontos de contato, assemelhando-se por sua tendência antimetafísica e pelo empirismo radical (REALE, 2008, p. 458). 
InterAção | 59

No que concerne à obra teórico-literária, verifica-se que Kelsen publicou seu primeiro livro em 1911, intitulado Problemas capitais da teoria do direito estatal (no original, Hauptprobleme der Staatsrechsiehre entwickelt aus der Lehre vom Rechtssatze). Com esta obra, sua carreira como teórico legal começou a ter expressão no meio acadêmico, sendo possível encontrar neste trabalho bases da sua teoria pura do direito, as quais seriam aprofundadas em sua obra magna: Teoria Pura do Direito.

Destarte, tem-se que a obra de maior denodo de Kelsen é a Teoria Pura do Direito, que consiste na condensação de todos os estudos do autor acerca do direito, contando com quatro edições fundamentais - ou, como insinuam alguns críticos de Kelsen, quatro versões da mesma obra. Sua primeira edição, intitulada "Reine $R e-$ chtslehre" foi publicada em 1934, na cidade de Viena. Por sua vez, a segunda foi editada pela Universidade de Harvard em 1945, com o nome "General Theory of Law and State", e a terceira foi a edição francesa, publicada na Suíça, em 1953, chamada "Théorie Pure du Droit" (MOREIRA, 2009, p. 281).

A quarta e definitiva edição, foi a chamada segunda edição alemã de "Reine Rechtslehre", publicada em 1961, e, tal como a primeira, restou editada na cidade de Viena, registrando um maior aprofundamento em diversos pontos e um refinamento nas noções básicas de sua teoria pura, inclusive chegando a modificar alguns de seus posicionamentos inicialmente sustentados quando da edição de 1934.

Logo, considerando a importância e o caráter compilador de Teoria Pura do Direito, em especial a abordagem desempenhada pelo autor acerca da relação entre o direito e a ciência, tem-se que justifi- 
60 | InterAção

cado o estudo ora empreendido, o qual possui por objeto o exame e apreciação crítica desta relação entabulada entre o direito e a ciência.

\section{Teoria pura do direito: aspectos introdutórios}

O mote inicial de Teoria Pura do Direito, enquanto marco teórico, se situa quando Hans Kelsen enfaticamente eleva o Direito a uma categoria científica autônoma. Para tanto, apõe uma depuração do objeto da ciência jurídica, em especial de toda ideologia política, moral e dos elementos de ciência natural, ou seja, uma teoria jurídica pura pautada na neutralidade científica. Assim, alicerça sua proposição nos ideais de objetividade e especificidade, levados a termo pelo autor através da definição das normas jurídicas como objeto da ciência jurídica, sublinhando, ainda, se tratar de ciência jurídica e não política do Direito (KELSEN, 2009, p. 79).

Oportuno ressaltar, neste aspecto, que esta pureza sugerida por Kelsen não se cinge ao objeto do estudo, mas igualmente enquanto método, conforme anota Moreira:

Metodologicamente Kelsen é detalhista, minucioso, repetitivo, extraordinariamente lógico. Foi um defensor da neutralidade científica aplicada à ciência jurídica. Sempre insistiu na separação entre o ponto de vista moral e político. A ciência do Direito não caberia fazer julgamentos morais nem avaliações políticas sobre o direito vigente. Com o objetivo de discutir e propor os princípios e métodos à teoria jurídica - até então inexistentes - aliado à necessidade de dar ao Direito uma autonomia científica própria, capaz de superar as confusões metodológicas da livre interpretação do direito, uma tendência à um retorno aos parâme- 
InterAção | 61

tros do direito natural ou mesmo a aplicação de critérios de livre valoração, Kelsen propõe o que denominou princípio da pureza.

O princípio da pureza aplica-se portanto tanto ao método como ao objeto do estudo, ou seja é instituto instrumental e delimitador da ciência jurídica, significando que a premissa básica desta é o enfoque normativo. $\mathbf{O}$ direito para o jurista deveria ser encarado como norma (e não como fato social ou como valor transcendental) (MOREIRA, 2001, texto digital).

Corrobora com a tese aludida, a própria manifestação de Kelsen no prefácio à primeira edição, quando afirma ser seu objetivo formular uma teoria pura do direito, i.e., purificada de toda ideologia política e dos elementos de ciência natural, consciente da legalidade específica do seu objeto. Esclarece, ainda, que sua luta se trata, de fato, pela relação entre ciência jurídica e a política, pela rigorosa separação entre elas, pela renúncia ao costume de, invocando-se a égide da ciência do Direito e, apelando a uma suposta objetividade, advogar postulados políticos de caráter deveras subjetivo (KELSEN, 2009, pp. XI-XII).

E isso implica a diferenciação entre a Teoria Pura do Direito e a ciência jurídica tradicional, a qual, variavelmente, possui um caráter ideológico. Notadamente, por sua tendência antiideológica, revela-se a teoria pura do direito como verdadeira ciência do Direito. Com efeito, conforme elucida Wolkmer, "a ciência tem, como conhecimento, a intenção imanente de desvendar seu objeto. A 'ideologia', porém, encobre a realidade enquanto [...] a desfigura." (2002, p. 164).

Note-se, portanto, que a importância da teoria pura do direito formulada por Kelsen consiste justamente no rompimento com os 
62 | InterAção

paradigmas até então adotados no período, o jusnaturalismo, assim como o realismo jurídico, através do estabelecimento de uma ciência jurídica autônoma e neutra de quaisquer influências político, morais, sociais e de outras ciências. $\mathrm{Na}$ mesma medida, o autor sugere uma ciência do direito alicerçada em proposições normativas que descrevem sistematicamente o direito, ou seja, nas palavras de Rocha (2005, p. 16), "propõe uma ciência do direito como uma metalinguagem distinta de seu objeto".

Sem embargo, afere-se que este ideal de ciência pura restou delineado no capítulo terceiro de Teoria pura do direito, possuindo como uma de suas diretrizes epistemológicas fundamentais o dualismo kantiano, entre ser e dever ser, no qual os juízos de realidade e juízos de valor restam contrapostos. Seguindo a orientação neo-kantiana, Kelsen elegeu a edificação de um sistema jurídico centrado exclusivamente no mundo do dever ser. No entanto, tal escolha acarreta na superestimação dos aspectos lógicos constitutivos da teoria pura, em detrimento dos suportes fáticos do conhecimento ( $\mathrm{RO}-$ CHA, 2005, p. 16).

\section{0 direito e a ciência apresentados na Teoria pura do direito}

$\mathrm{Na}$ presente seção serão apontadas, brevemente, as principais ideias de Kelsen acerca do Direito e a ciência, as quais foram articuladas no terceiro capítulo de sua obra magna, de igual nomenclatura - Direito e ciência.

$\mathrm{O}$ autor inicia o supramencionado capítulo esclarecendo que o objeto da ciência jurídica cinge-se nas normas jurídicas, sendo a conduta humana apenas quando configurar conteúdo da norma ju- 
rídica, ou seja, a ciência jurídica procura apreender o seu objeto juridicamente, sob o ponto de vista do Direito. Isso porque, em suas palavras, afirma que “[...] apreender algo juridicamente não pode, porém, significar senão apreender algo como Direito, o que quer dizer: como norma jurídica ou conteúdo de uma norma jurídica, como determinado através de uma norma jurídica." (KELSEN, 2010, p. 79).

No que concerne à conduta humana, observa o pensador austríaco, enfatizando que esta apenas o será objeto da ciência jurídica quando configurar o próprio conteúdo da norma jurídica seja enquanto pressuposto ou consequência, representando assim uma interpretação normativa destes fatos de conduta.

Logo, para compreender a teoria do ordenamento jurídico proposta por Hans Kelsen, necessária se faz traçar a distinção entre norma jurídica (Rechtsnorm) e proposição jurídica (Rechtssatz).

Com efeito, tem-se que as normas jurídicas não são juízos, nem tampouco traduzem, diretamente, nenhum comando ou imperativo. Isso porque, a norma é logicamente indicativa e de estrutura hipotética, uma vez que se limita a ligar um fato condicionante a uma consequência - a sanção -, sem enunciar qualquer juízo a respeito do valor moral ou político dessa conexão. Assim, se a lei natural discorrer que: se A é, B tem de ser; a lei jurídica, por seu turno, irá declarar: se A é, B deve ser, sendo que a ligação «deve ser» significa uma forma de conexão inequívoca com a do nexo entre causa efeito.

Note-se que o sentido deste ato é diverso do sentido da proposição jurídica, juízo hipotético, descreve as relações constituídas, através das normas jurídicas, entre os fatos por elas determinados, ou seja, descreve o Direito, não importando a forma de exteriorização 
do enunciado, mas seu sentido. A norma jurídica, editada pela autoridade, tem caráter prescritivo e consiste na manifestação de ato de vontade, enquanto a proposição jurídica, emanada da doutrina, tem natureza descritiva e decorre de ato de conhecimento. A função significativa de uma norma jurídica, portanto, não é enunciar, porém prescrever determinado comportamento humano, i.e., impor um dever (DINIZ, 2003, p. 69).

Mister destacar, ainda, a observação de que Kelsen situa as normas jurídicas no plano da validade, atraindo para estas a aplicação dos princípios lógicos, em especial o princípio da não contradição e as regras da concludência do raciocínio. Isso se dá, uma vez que tais princípios são aplicáveis unicamente à proposição cujo resultado seja falso ou verdadeiro - e as proposições da ciência jurídica enquanto prescrições são válidas ou inválidas.

Daí, possível compreender a crítica do pensador austríaco às proposições de uma teoria metafísica do direito e sua observação de que, limitada às descrições normativas, à ciência jurídica não cabe investigar a eficácia da norma, mas tão somente se pronunciar acerca de sua validade formal, ou se possui vigência. Isso porque, ao discorrer se determinada norma é ou não vivenciada como regra social, estaria emitindo juízos referentes à ordem do ser, juízos sobre a realidade, o que fere seu propósito de pureza (NOLETO, 2002, texto digital).

\section{Causalidade e imputação}

A concepção normativista e seu ideal de pureza formulados por Kelsen têm como uma de suas bases a diferenciação entre lei da natureza e norma jurídica. Isso porque, no mundo do ser (Sein), 
InterAção | 65

na natureza os sistemas de elementos estão interligados entre como causa e efeito, isto é, pelo princípio da causalidade, que prescreve que “quando é A, B também é (ou será)". A relação entre pressuposto e consequência está expressa na lei natural, não é produzida (KELSEN, 2010, p. 100).

Nestes termos, cumpre-se destacar a lição de Rocha, o qual traz à baila tal dicotomia fundamental entre ser e dever ser no pensamento de Hans Kelsen, in verbis:

A TPD (Teoria Pura do Direito) tem, como uma de suas diretrizes basilares, o dualismo metodológico Kantiano, entre ser/dever ser. [...] Como sabemos, entre os juízos de realidade e os juízos de valor, Kelsen, fiel à tradição relativista do neo-Kantismo, de Marburgo, optou pela construção de um sistema jurídico centrado unicamente no mundo do dever ser. Tal ênfase, acarretou a superestimação dos aspectos lógicos constitutivos nas análises Kelsenianas, em detrimento dos suportes fáticos do conhecimento (ROCHA, 1984, p. 60).

A conduta humana se situa no mundo do dever ser (Sollen), devendo ser entendida como ordem normativa da conduta dos homens entre si, estando sob a égide do princípio da imputação, do qual se atribui uma consequência em razão da prática de determinado ato. O esquema estrutural das normas jurídicas e morais, constituindo-se numa proposição, é diverso daquele das leis físico-naturais, pois, como afirma Kelsen (2010, p. 100), “quando é A, B deve ser”, inclusive por força do princípio da imputação. Sua relação de pressuposto e consequência se dá por meio de uma norma posta pelos homens, porém independente de toda a intervenção desta espécie, ou seja, com interferência e definição a partir da vontade e liberdade humanas. 
66 | InterAção

Com efeito, verifica-se que a norma jurídica não preceitua um juízo de valor, todavia apenas comina uma sanção ou consequência no caso de se preferir conduta contrária à juridicamente devida. Como adverte Reale (2008, p. 461), o "fazer é algo que não pertence ao campo estritamente jurídico: quando um homem pratica certo ato, age por motivos que não são jurídicos.”.

Para Kelsen, a norma jurídica possui uma estrutura lógica com a forma do dever ser lógico, consistente na imputação de uma consequência a um suposto fato. Nessa perspectiva, constata-se que o autor apoia sua teoria no denominado princípio da imputação. Tendo por base a liberdade, essencial para as relações humanas e requisito indispensável da imputação, o princípio da imputação caracteriza-se como uma relação normativa ou de imputação, cujos elos desta série imputativa são limitados.

Gize-se que a sobredita liberdade se refere ao homem, como personalidade jurídica ou moral, livre e, portanto, responsável. A imputação encontra seu ponto terminal na conduta do homem, interpretada como ato meritório, como pecado ou ilícito. Segundo Kelsen (2010, p. 104), "sua vontade é causa de efeitos, mas não é ela mesma o efeito das causas.", concluindo que não se imputa algo ao homem porque ele é livre; mas ao contrário, o homem é livre porque se lhe imputa algo.

De outra banda, o princípio da causalidade está atrelado a uma relação causal, cuja base se fulcra na necessidade. A cadeia de causa e efeito é interminável, pois na natureza toda causa pressupõe como efeito uma outra causa; e todo efeito deve ser considerado como causa de um outro efeito concreto. Note-se que o homem enquanto 
InterAção | 67

parte da natureza não é livre, ou seja, sua conduta, considerada como fato natural, é por força de uma lei da natureza, causada por outros fatos.

Por conseguinte, um indivíduo será moral ou juridicamente responsável por um evento quando provocado por seu ato de vontade ou pela omissão de um ato de vontade que evitaria o evento, estando a imputação e a liberdade ligadas essencialmente entre si. O homem é livre porque sua conduta determina à imputação, ainda que seja casualmente determinada. Logo, não contradição entre causalidade da ordem natural e a liberdade sob a ordem moral ou jurídica, tendo em conta que a primeira é uma ordem do ser e as outras são ordens do dever ser, e apenas podem haver contradições entre um ser e um ser, ou entre um dever ser e um dever ser, enquanto objeto de asserções ou enunciados (KELSEN, 2010, p. 110).

\section{A negação do dever ser e o Direito como ideologia}

$\mathrm{Na}$ segunda edição de Teoria Pura do Direito, Hans Kelsen buscou aprofundar seus posicionamentos adotados na primeira edição obra, por vezes redefinindo conceitos como por outras vezes recolocando-os, a fim de evitar mal entendidos que motivavam repúdio à sua teoria, mas especialmente buscou esclarecer muitas das críticas sofridas.

No que se refere ao capítulo em análise - Direito e ciência, Kelsen arrazoou acerca da tese suscitada por seus opositores, na qual a possibilidade de uma ciência normativa é posta em questão sob o argumento de que o conceito de dever ser, cuja expressão é a norma, seria sem sentido ou se constituiria em mera ilusão ideológica. 
68 | InterAção

Com efeito, na construção de uma ciência do Direito, efetuada através da identificação de objeto próprio de estudo do Direito, depurado de toda e qualquer variável que não pertença ao Direito, Kelsen tece distinção fundamental entre a Sociologia do Direito, cujo objeto foca-se nos fenômenos paralelos da natureza, i.e., nos fatos da ordem do ser, e a Teoria Pura do Direito, que se ocupa das normas jurídicas, descrevendo o dever ser da norma. A Ciência Normativa, por seu turno, é aquela que descreve o Direito como sistema de normas, no qual o dever ser é expresso na norma.

Logo, ao se referir que se trata de ilusão ideológica, significa que impossível uma ciência jurídica normativa ou apenas possível enquanto compreendida como sociologia jurídica. Nesta ótica, os atos jurídicos são tomados apenas na sua facticidade, não levando em conta o sentido específico de seu teor. Todavia, Teoria Sociológica jurídica ocupa-se com os fatos da ordem do ser, não colocando em relação às normas válidas. Em outros termos, descreve a conexão causal entre quaisquer fatos políticos ou econômicos e atos produtores de direito, assim como entre atos produtores de direito e a conduta humana visada - quando motivada pela representação da intenção de um ato -.

No entanto, conforme explicita Kelsen, a proposição jurídica que descreve o direito não se cinge em mero significado de uma conexão funcional específica. Isso porque, na imputação há conexão funcional distinta daquela decorrente do nexo causal, pois os fatos que a imputação jurídica conexiona entre si são diversos, na medida em que a imputação jurídica liga o fato, determinado pela ordem jurídica, com a consequência fixada pela mesma ordem jurídica.

Portanto, ao se considerar o direito como ideologia, tem-se 
InterAção | 69

que este não seria exigível, ou seja, que as normas jurídicas não seriam aplicáveis, assim como seria equivocada, vez que a ideologia é por si mesma equivocada. Destarte, esta formulação acaba por distanciar-se da neutralidade apregoada pelo autor em sua teoria pura do direito, de forma que, nas palavras de Wolkmer, “[...] toda e qualquer sistematização jurídica que não seja a 'teoria pura normativa' [...] resulta em formulações ideológicas." (2002, p.164). Tal ilusão possui vez, contudo, quando, com o dever ser jurídico, se afirme um valor moral absoluto.

No que concerne à negação do dever ser, i.e., do conceito do dever ser como algo sem sentido, equivaleria declarar que os atos de produção jurídica apenas podem ser conhecidos como meios de provocar determinada conduta dos indivíduos a quem se dirigem tais atos. Ou seja, o sentido jurídico positivo torna-se equivalente ao sentido moral, perdendo-se o sentido na afirmação de que algo "deve ser”. Entretanto, verifica-se que tal posição encontra óbice no fato de que as normas são imperativas.

\section{Críticas à teoria de Kelsen}

A tese formulada por Hans Kelsen, em que defende uma ciência do Direito, com objeto próprio de estudo do Direito e livre de toda e qualquer influência da ideologia política e dos elementos da ciência natural, bem como sua proposição de que o Direito deveria ser apreendido como norma e não como fato social, foi recepcionada na época de sua publicação com grande polêmica e ressalva.

Uma das críticas cardiais sofridas por Kelsen diz respeito à 


\section{0 | InterAção}

denúncia de que sua teoria seria deveras reducionista quanto ao objeto jurídico e a natureza puramente normativa ventiladas pelo autor, de forma a olvidar as dimensões sociais e valorativas, relegando o fenômeno jurídico a uma mera forma normativa. De fato, a cientificidade e pureza propaladas pelo mestre normativista não deixam, também elas, de serem consideradas ideologias por si próprias, uma vez que transforaram-se em instrumentos de legitimação de inúmeras ordens político jurídicas (WOLKMER, 2002, p. 166).

Para Warat, o caráter idealista da teoria pura de Kelsen, sob a égide epistemológica, se denota a partir da não-diferenciação entre o idealismo - ou metafísica - e o positivismo, vez que, para o referido autor, este seria tão-somente uma forma de idealismo, afirmando que:

[...] A fusão de algumas ideias do kantismo com outras do positivismo determinou um processo dialético entre ambas as posturas, cuja síntese é a teoria pura do Direito. Isto é, um pensamento relativamente distante e reformulado dos pressupostos indicados. Quaisquer que sejam as variantes introduzidas nas diversas versões da teoria pura, durante a longa vida de Kelsen, o saldo teórico não deixa de ser um pensamento idealista, e isto porque, tanto o processo positivista do conhecimento (em sua forma experimental ou em sua modalidade lógica) como o racionalismo (em sua forma pré-gnoseológica e dogmática ou transcendental) têm como base a mesma problemática epistemológica, definem a mesma temática fundamental e ao mesmo tempo evitam possíveis relações da teoria com a realidade.

Por razões epistemológicas, sustento a tese de que o positivismo é uma forma de idealismo, porquanto diacronicamente define sua problemática através de um movimento duplo: racional e empírico, conceitual e referencial, que, aceitando sua dialé- 
InterAção | 71

tica, ao mesmo tempo está desprezando tanto o idealismo puro como o empirismo ingênuo. Consequentemente, temos como síntese um idealismo crítico que não admite um conhecimento exclusivamente processado pelo pensamento sem fazer referência à experiência para constituir a razão em fator determinante do conhecimento a partir da experiência; e um positivismo lógico, que se distancia dos dados sensíveis, desembocando em um conceitualismo vazio e formal, que se conforma com um controle sintático da realidade.

A Teoria pura do Direito, ao ser reduzida a um conceitualismo presente tanto no idealismo crítico como no positivismo lógico, consegue eliminar de sua problemática a discussão sobre os fatores co-determinantes da realidade jurídica, como também sobre o papel social e político do Direito e as dimensões ideológicas dos diversos discursos enquanto prática jurídica concreta (WARAT, 1995, pp. 131-132).

Importa observar, ainda, outra objeção fundamental em Kelsen, qual seja a impossibilidade de proceder com a separação rígida entre o mundo do ser e do dever ser, concebidos como categorias ontológicas radicalmente distintas. Isso porque, entre ser e dever ser existe um nexo de implicação e polaridade, o que torna compreensível a complementariedade dialética própria do Direito, mantendo-se, porém, infenso a qualquer apreensão deste tipo.

Logo, o embasamento lançado pelo filósofo, de um formalismo normativista abstrato, vai de encontro com um dos fundamentos inerentes à essência do próprio Direito: a matéria social regulada. De fato, tem-se que a ciência jurídica deve se ocupar na elaboração de uma racionalidade prática na definição de critérios e mecanismos razoáveis de decisão, sob pena de recair no relativismo imposto pelo positivismo. 


\section{2 | InterAção}

$\mathrm{Na}$ esteira desse raciocínio, certeira é a lição de Reale, que enfrenta com muita propriedade tal questão, argumentando que:

Ora, é impossível focalizar-se o problema da funcionalidade de dever ser e ser, como assunto de Teoria do Direito, sem necessariamente se ultrapassar a esfera da Lógica Jurídica, ou seja, sem se correlacionar o que está prescrito na norma jurídica in abstracto com o que ela efetivamente representa no plano concreto dos comportamentos humanos.

À margem desta questão, não é demais repetir duas observações fundamentais, que se completam: é verdade que do mundo do ser não se pode passar para o dever ser, porque aquilo que é não se transforma naquilo que deve ser; a recíproca, porém, não é verdadeira, porque o dever ser, que jamais possa ou venha a ser, é sonho, é ilusão, é quimera, não é dever ser propriamente dito. Quando reconhecemos que algo deve ser, não é admissível que jamais venha a ser de algum modo. Um dever ser que nunca se realize parcialmente é uma abstração sem sentido. $\mathrm{O}$ que acontece, porém, é que, por outro lado, jamais o dever ser poderá converter-se totalmente em ser. Para que haja dever ser, é necessário que o ser jamais o esgote totalmente [...] (REALE, 2002, p. 469).

Vislumbra-se, portanto, o caráter de distanciamento da realidade que assume o filósofo austríaco, por sua proposição de que o direito deve ser encarado como juízo hipotético formalmente elaborado composto por dois elementos ligados pela cópula do dever ser, a despeito da necessária postura que os sistemas jurídicos, na qualidade de conjuntos de premissas mutáveis, devem conservar de uma textura abertura em relação à constante atualização das questões relacionadas à sociedade e a justiça. 
InterAção | 73

Em que pese às censuras pela impossibilidade prática de separação do ser e dever ser, urge-se destacar a oportuna anotação de Rocha, no sentido de que Kelsen não nega a complexidade do mundo, tendo como escopo a investigação por uma metalinguagem para elaboração de uma teoria capaz de reduzir a complexidade social, argumentando que:

Kelsen, ao contrário do que pensam seus críticos apressados, por filiar-se à tradição da "teoria do conhecimento", assume como inevitável a complexidade do mundo em si. Para ele, o social (e o direito) são devido as suas heteróclitas manifestações constituídas por aspectos políticos, éticos, religiosos, psicológicos e históricos. $\mathrm{E}$ a esse respeito não cabe ao cientista do direito nada comentar. $\mathrm{A}$ função do cientista é a construção de um objeto analítico próprio e distinto destas influências. A partir desta constatação é que Kelsen vai procurar, assim como Kant, depurar essa diversidade e elaborar uma "ciência do direito". Ou seja, na teoria pura uma coisa é o direito, outra distinta é a ciência do direito. $\mathrm{O}$ direito é a linguagem objeto e a ciência do direito a meta-linguagem: dois planos lingüísticos diferentes (ROCHA, 2003, P. 72).

Afere-se, portanto, o intransponível argumento de que o $\mathrm{Di}^{-}$ reito é indissociável da comunicação com outros ramos e ciências, em particular a ética, na medida em que se dirige à conduta social do homem no complexo da realidade social e se coaduna, enquanto caráter de valor, na qual sua fonte comum axiológica é próprio homem. Assim sendo, tem-se que superada a tese do filósofo austríaco na qual o Direito deveria se limitar às descrições normativas, posto que o jurista quando procede com a imputação, acaba necessariamente por compreender a norma aplicando sua interpretação. 
Nessa direção, desdobram-se as posições de Viehweg e Perelman. Para Viehweg, o sistema jurídico, isto é, o Direito efetivo realidade normativa passível de descrição científica, segundo orienta Kelsen - é algo desde logo impuro, corrompido pela interpretação do jurista, que é um tipo de pensamento que deve, conforme Viehweg, mover-se dentro do estilo da tópica $(1979$, p. 89).

Perelman, por seu turno, também comunga a opinião de que a teoria pura articulada por Hans Kelsen é maculada, pois depende de decisões, de atos de vontade, que não se fundam em direito, mas se justificam por considerações de ordem política ou moral.

Corrobora o argumento suscitado, igualmente, a questão acerca da validade e eficácia das normas jurídicas, as quais dependem para serem consideradas válidas em um sistema jurídico de sua constatação prática e vivência social. Ou seja, um sistema jurídico existe, enquanto tal, unicamente como realidade social, que por sua vez consiste no fato que a população aceita e obedece a certas normas.

Em complementação, importa ressaltar que a estrutura lógica da norma não se confunde com sua existência real e concreta. Isso porque, a norma não se esgota como estrutural formal ou, nas palavras do mestre austríaco, trata-se de uma pura proposição lógica de natureza ideal. Mas, ao revés, afigura como momento culminante da experiência jurídica, com existência real, no tempo e espaço, com finalidades e valores implícitos.

A objeção última que se estabelece na teoria de pureza do Direito, diz respeito ao fracasso da tentativa da matriz analítica, na qual se classifica o ideal kelseniano, em elaborar uma linguagem pura para o direito. Isso porque, adotando-se a classificação propedêutica de Ro- 
InterAção | 75

cha (2005, pp. 15-16) das matrizes teórico-jurídicas de acordo com a sua inserção semiótica, contempla-se que a teoria kelseniana encontra guarida na filosofia analítica enquanto desdobramento da sintaxe, em consequência de seu postulado de uma ciência do direito alicerçada em proposições normativas que descrevem sistematicamente o objeto direito, ou seja, através da análise lógico formal das normas jurídicas.

Entretanto, verifica-se que tal matriz segue uma postura de neutralidade no tocante aos seus aspectos políticos, provocando consequências teóricas graves, devido a sua incapacidade de pensar uma complexidade social mais ampla.

Dessa feita, a filosofia analítica normativista, baseada em critérios sintático-semânticos, conforme proposto por Kelsen em Teoria Pura do Direito, passou a enfrentar dificuldades ante ao surgimento de novos anseios teórico-sociais. Em resultado às exigências, a filosofia analítica iniciou um processo de reestruturação, a fim de voltar-se para a análise de critérios pragmáticos de racionalidade.

\section{CONSIDERAÇÕES FINAIS}

A despeito das críticas formuladas à teoria de pureza apregoada por Hans Kelsen, tem-se que inegável a importância e genialidade de seu pensamento na determinação das construções lógico-formais da Ciência Jurídica, em especial no rompimento de paradigmas vigentes em sua época, desqualificando o direito natural como teoria válida do Direito, além das inumeráveis contribuições na seara da dogmática, tais como na reformulação dos conceitos e objetivo do próprio Direito fomentados por suas ideias revolucionárias. 
76 | InterAção

Nem demais notar, desde logo, que a problemática em torno da objetividade científica do direito atualmente se encontra no cerne de discussões do chamado neopositivismo ou pós-positivismo, em particular considerando as novas abordagens epistemológicas acerca do direito e sua ciência, com notável acento na hermenêutica jurídica, e contando com o desenvolvimento da filosofia da linguagem e da argumentação jurídica. Logo, afere-se que o tema ainda persiste fascinante quanto controvertido.

Nesta perspectiva, a tomada de uma posição ligada ao normativismo e ao Estado pode se tornar extremamente limitada. $\mathrm{Na}$ lição de Rocha "não se pode assim continuar mantendo uma noção de racionalidade no Direito ao se insistir no ideal kelseniano" (2007, texto digital).

A guisa de conclusão, impõe-se destacar a necessidade premente de se produzir uma epistemologia construtivista que tenha como fundamento a temática da pluralidade social, partindo-se da premissa da complexidade do mundo em si, dos paradoxos e riscos, a fim de tentar superar - ou ao menos contornar - a crise instaurada no Direito e suas instituições. Isso porque, a crise do Direito não se insurge de mera deficiência em sua estrutura tradicional, contudo, ao revés, tal crise emerge de igual forma da ausência de integração dos seus pressupostos dogmáticos e as necessidades decorrentes da sociedade globalizada - os chamados novos direitos.

\section{REFERÊNCIAS}

DINIZ, Maria Helena. Conceito de norma jurídica como problema de 
InterAção | 77

essência. 4. ed. São Paulo: Saraiva, 2003.

KELSEN, Hans. Teoria pura do direito. Trad. João Baptista Machado. 8. ed. São Paulo: WMF Martins Fontes, 2009.

NOLETO, Mauro Almeida. Direito e Ciência na Teoria Pura do Direito de Hans Kelsen. Jus Navigandi, Teresina, ano 7, n. 54, 1 fev. 2002. Disponível em: <http://jus.uol.com.br/revista/texto/2644>. Acesso em: 10 jul. 2011.

MOREIRA, Felipe Kern. A ciência do Direito em Hans Kelsen: Abordagem filosófico-crítica. In: Âmbito Jurídico, Rio Grande, 7, 30 nov. 2001 [Internet]. Disponível em: <http://www.ambito-juridico.com. br/site/index.php?n_link=revista_artigos_leitura\&artigo_id $\quad=5516>$. Acesso em 11 jul. 2011.

A construção teórica do conceito de legitimidade no direito internacional: a inaplicabilidade da Norma Fundamental da Teoria Pura do Direito de Hans Kelsen. Brasília: UNB, 2009, 602 f., il. Tese (doutorado) - Programa de Pós-Graduação em Relações Internacionais, Instituto de Relações Internacionais, Universidade de Brasília, Brasília, 2009.

PERELMAN, Chaïm. A Teoria Pura do Direito e a Argumentação. Tradução: Ricardo R. de Almeida. Rio de Janeiro. Disponível na internet: <http:/www.puc-rio.br/sobrepuc/dpto/direito/pet_jur/ c1perelm.html>. Acesso em: 19 jul. 2011.

REALE, Miguel. Filosofia do direito. 20. ed. 5. tiragem. São Paulo: Saraiva, 2008.

ROCHA, Leonel Severo. A Produção Sistêmica do Sentido do Direito: da Semiótica à Autopoiese. In: Constituição, Sistemas Sociais e Hermenêutica. Anuário do PPG em Direito da UNISINOS. v. 6. Porto 
Alegre: Livraria do Advogado, 2009.

Da Epistemologia Jurídica Normativista ao Construtivismo Sistêmico. In: ROCHA, Leonel Severo; SCHWARTZ, Germano; CLAM, Jean. Introdução à Teoria do Sistema Autopoiético do Direito. Porto Alegre: Livraria do Advogado, 2005.

Entre o Normativismo e a Sociedade: Percursos do Direito a procura de sua Unidade. Disponível na internet: < http://www.unisinos. br/pastanet/arqs/0450/1606/texto ied20071.doc >. Acesso em: 05 jul. 2011.

Epistemologia jurídica e democracia. 2. ed. São Leopoldo: Unisinos, 2003.

O Sentido Politico da Teoria Pura do Direito. In: Seqüência (Florianópolis), Florianópolis, v. 9, p. 57-75, 1984.

SCHWARTZ, Germano André Doederlein. Considerações sobre a teoria kelseniana. In: GRUNWALD, Astried Brettas (org.). Revista do Curso de Direito. v. 5, n. 5 (jan./dez.) - Cruz Alta: UNICRUZ, 2000.

VIEHWEG, Theodore. Tópica e jurisprudência. Brasília: Ministério da Justiça e Universidade de Brasília (co-edição): 1979.

WARAT, Luis Alberto. Introdução geral ao direito II: a epistemologia jurídica da modernidade. Tradução de José Luiz Bolzan de Morais. Porto Alegre: Sergio Antonio Fabris Editor, 1995.

WOLKMER, Antonio Carlos. Introdução ao pensamento jurídico crítico. 4. ed. São Paulo: Saraiva, 2002. 